\title{
SURDEZ E INCLUSÃO SOCIAL: O QUE AS BRINCADEIRAS INFANTIS TÊM A NOS DIZER SOBRE ESSE DEBATE?
}

\author{
Daniele Nunes Henrique Silva*
}

RESUMO: O presente artigo analisa questões pertinentes ao modo de funcionamento lúdico de crianças surdas, na fase inicial de aquisição da língua de sinais, tendo como pressuposto teórico as formulações da corrente histórico-cultural e as contribuiçôes conceituais de M. Bakhtin. A atenção volta-se, especialmente, para os modos de configuração dos personagens (jogo de papéis), evidenciando a forma como os elementos do universo ouvinte são incorporados nas brincadeiras. Num desdobramento, a partir do exame de material videogravado (episódios de faz-de-conta), busca-se refletir criticamente sobre as concepções de inclusão social que tangenciam a experiência do surdo, alertando para o fato de que a criança já demonstra em suas brincadeiras o desejo e a necessidade de pertencimento à sociedade ouvinte majoritária.

Palavras-chave: Surdez. Brincar. Educação de surdos. Criança surda. Inclusão social.

DEAFNESS AND SOCIAL INCLUSION:

WHAT DO CHILDREN'S GAMES HAVE TO TELL US ON THIS DEBATE?

ABSTRACT: Theoretically based on the formulations of the historical-cultural trend and the conceptual contributions of M. Bakhtin, the present paper analyzes issues related to the play activities of deaf children in the initial phase of sign language acquisition. Attention is especially paid to the way characters (role-play) are configured, highlighting how the elements of the hearing universe are incorporated to the games. The examination of videotaped material (scenes

* Doutoranda em Educação pela Universidade Estadual de Campinas (UNICAMP) e coordenadora do Programa de Pós-Graduação Lato Sensu "Educação em Ação", da Universidade Candido Mendes (RJ).E-mail: dnunes@candidomendes.edu.br

Disponível em <http://www.cedes.unicamp.br> 
Surdez e Inclusão Social: o que as brincadeiras infantis têm a nos dizer...

of playing pretend) then led us to reflect critically on the conceptions of social inclusion linked to the experience of the deaf, stressing the fact that, in their games, the children already demonstrates their desire and need to belong to the majority hearing society.

Key words: Deafness. Playing. Education of the deaf. Deaf child. Social inclusion.

\section{Introdução}

$I$ nspirado pelas idéias centrais de Marx (1971, 1999), o psicólogo Vigotski (1999 e 2000) buscou romper com as concepções dualistas sobre o desenvolvimento humano vigentes no início do século $\mathrm{XX}$. O autor centralizou o foco de sua análise na intrínseca relação da esfera social e histórica para compreensão do funcionamento psíquico de ordem superior.

Nessa linha argumentativa, a especificidade humana só pode ser explicada como atrelada ao advento da cultura, mais especialmente do trabalho social; gerador da necessidade de trocas interpessoais e da criação coletiva de sistemas simbólicos. A consciência não é uma energia anterior/superior em si, não é inata, pois se constituiu nos processos de apropriação e criação da esfera cultural.

Os processos cognoscitivos não são mais concebidos como vinculados exclusivamente à experiência individual, como tradicionalmente tratou a psicologia, mas, pelo contrário, eles são radicalmente transformados pelos intercâmbios sociais, consolidados nos processos de significação da palavra/do mundo.

Em função disso, na elaboração de suas teses gerais, Vigotski (1987) buscou evidenciar vários processos específicos do funcionamento ontogenético (memória, percepção, atenção etc.), focalizando suas relações com as condições sociais concretas e a atividade simbólica que o constituíam. Uma dessas esferas, que se vincula ao interesse central do presente trabalho, diz respeito à imaginação. ${ }^{1}$

Vigotski (2000) discutirá as questôes da imaginação de forma bastante ousada para a sua época. Para ele, diferente de seus contemporâneos, a capacidade de imaginar não depende da memória, não está presa (de forma reprodutiva) às percepçóes do passado, ou impressōes acumuladas anteriormente. A imaginação é, prioritariamente, a capa- 
cidade do homem de criar, mesmo se baseando na experiência passada, elementos novos. Mas o que motiva a emergência de açôes criativas? Por que os homens imaginam e criam?

O principal fator psicológico do desenvolvimento da imaginação baseia-se na necessidade que o homem experimenta de adaptar-se ao ambiente que o rodeia. Se o ambiente não oferecesse nenhum obstáculo, nenhuma indagação, não haveria base alguma para o surgimento de uma ação criadora. Mas, ao contrário, a inadaptação ao ambiente é a condição principal para a emergência da imaginação. É exatamente a atividade criadora que permite a projeção do futuro, a constituição de um ser que modifica suas condições presentes.

A produção de imagens e todo o processo psicológico que envolve a imaginação e a criação não estão dissociados das condiçōoes de vida do homem, das suas necessidades e desejos. Por isso, toda atividade criadora parte da experiência, ou melhor, da forma como o sujeito percebe internamente e externamente o mundo.

Para a criança pequena, por exemplo, os primeiros pontos de apoio para a futura criação estão naquilo que ela ouve e vê, acumulando materiais que usará para compor seu cenário de fantasia, a partir da dissociação e associação de impressões percebidas. Porém, a criança não repete o que ouve e vê. Tudo que ela imagina, mesmo quando se reporta à realidade, apresenta algo de criativo, muitas vezes, inaugural.

Para o autor, dentre as atividades guiadas pela imaginação, as açôes lúdicas revelam-se como importante interesse para os estudos em psicologia do desenvolvimento. Ao brincar, as crianças em idade pré-escolar envolvem-se em processos criativos, na medida em que recriam aspectos do mundo adulto, das vivências que têm socialmente, agindo além de suas competências habituais, além de seu comportamento diário.

A construção desse universo ilusório e imaginativo não emerge, entretanto, de motivações prazerosas e individuais, como suspeitou Piaget (1975). É a própria condição social da criança que a motiva em querer participar e entender o mundo da cultura, fazendo-a reproduzir, criando, aspectos desse real nas brincadeiras.

A necessidade de se apropriar das regras, dos valores sociais e de suas complexas relações impulsiona o surgimento de cenários lúdicos e da configuração de papéis/personagens; a criança faz-de-conta que é enfermeira, professora, mãe, filha, médico, motorista etc. 
Surdez e Inclusão Social: o que as brincadeiras infantis têm a nos dizer...

Ao mesmo tempo em que se apóia no real, por meio de regras e de generalizações de "papéis sociais" (tendo como base o que é externamente percebido da cultura), a criança efetua transformações, no nível simbólico, recompondo os significados, ultrapassando as condiçōes concretas impostas pelo real. Ela vê o objeto, mas, ao superar a determinação perceptual, sua ação passa a ser guiada pelo campo do significado. "A ação acaba surgindo das idéias e não das coisas" (Vigotski, 1988, p. 111). Nesse sentido, um lápis se transforma numa nave; uma pedra num posto de gasolina etc.

A criança pré-escolar não consegue separar o pensamento da presença de um objeto pivô (que serve para significar outro objeto). Por isso, utiliza-se de brinquedos para compor suas brincadeiras. O brinquedo, de fato, permite um estágio de transição em que ela pode simbolizar a realidade e agir para satisfazer seus desejos/necessidades.

Para além dessas possibilidades, o lúdico também pode ser interpretado como modo de expressão/representação da criança sobre o mundo, num formato de "leitura" e "escrita" (não-gráfica) sobre o real. Ler e escrever se consolidam por meio das impressōes que as crianças constroem sobre o seu universo cultural e histórico, representado nas brincadeiras por meio da composição de cenários, na assunção de papéis e organização da cena lúdica.

O corpo, os gestos, as palavras, toda a expressão infantil indica "o que ela escreve", tornando possível a qualquer outro "ler" o que ela percebe, o que ela quer fazer ser entendido. Tal esfera "autoral incipiente" permite a interpretação de que a brincadeira também está configurada por uma dimensão "embrionariamente artística", na medida em que envolve dois modos específicos de exploração da "experiência sensível" da criança:

a) Uma experiência "intencional" de "outridade" - A criança assume personagens, vivendo o lugar social do outro. Pode ser o outro, transitando por diferentes papéis sociais, como aponta Góes (2000, p. 123): "Ela brinca daquilo que já vivencia (filha); daquilo que ainda não pode ser (mãe, médica, professora); daquilo que o código social censura (ladrão, bêbado, seqüestrador); daquilo que aspira ser (pai, mecânico, astronauta); e assim por diante", ampliando a compreensão sobre si mesma e o mundo que a rodeia. 
b) Uma vivência "performática" incipiente - A criança, ao ser o outro, ao brincar de assumir papéis sociais, constrói cenários representados ou cenários conjeturais, ${ }^{2}$ que (também) podem estar direcionados para uma "platéia" fora do espaço da brincadeira, que está deslocada da cena, ou seja, para "o outro que a contempla na representação"; um parceiro, um adulto, ou mesmo um pesquisador.

Nesse sentido, Tezza (1996), por meio de uma detalhada discussão do capítulo "O autor e o herói" do livro $A$ estética da criação verbal (Bakhtin, 1992), sugere a existência de uma dimensão estética embrionária na experiência lúdica da criança pequena. O autor afirma (p. 290):

(...) quando, numa brincadeira coletiva, um garoto representa um bandido, outro mocinho etc. temos uma espécie de devaneio, mas nenhum acontecimento artístico. É só com o aparecimento do espectador, cuja observação agrega a atividade infantil num todo, numa unidade, que a mera representação começa a se transformar em atividade artística embrionária (...). ${ }^{3}$

A essa composição incipiente, às vezes semelhante à composição de um teatro, parece configurar-se um dos mais interessantes (e pouco explorados) aspectos da ludicidade, evidenciando sua possível conexão com o campo da arte. ${ }^{4}$

Apesar da dimensão artística/sensível ser ainda insuficientemente investigada no campo da atividade lúdica, a esfera entre o real e a fantasia já foi amplamente discutida em trabalhos investigativos que partem do pressuposto da abordagem sociogenética do brincar. Entre os autores contemporâneos, destacam-se as pesquisas realizadas por Oliveira (1988 e 1996), Pino (1996), Rocha \& Góes (1993), Rocha (2000), entre outros.

Entretanto, torna-se importante salientar que poucos estudos propóem-se a discutir os modos de funcionamento lúdico em crianças que apresentam peculiaridades no desenvolvimento. ${ }^{5} \mathrm{Na}$ verdade, os sujeitos portadores de deficiência são, geralmente, rotulados como incapazes de elaborar pensamentos desvinculados do concreto e, talvez, essa seja uma das explicaçōes para a escassez de investigaçôes que vinculem a experiência simbólica e o desenvolvimento de sujeitos considerados "deficientes".

No caso de crianças surdas, os estudos sobre os processos imaginativos, bem como os modos de configuração lúdica são ainda escas- 
Surdez e Inclusão Social: o que as brincadeiras infantis têm a nos dizer...

sos. As pesquisas já realizadas (Góes, 1997 e 2005; Ferreira, 1998) evidenciam que as investigaçôes sobre o brincar e a surdez revelam a constitutiva relação entre linguagem e atividade lúdica, apontando desdobramentos para as especificidades na maneira de organização do brincar em sujeitos que apresentam desenvolvimento lingüístico peculiar, como é o caso dos surdos. Além de relevante para os estudos na área do desenvolvimento, os trabalhos também demonstram desdobramentos importantes e discussão crítica para configuração de atendimentos terapêuticos e educacionais ofertados para esse público, ampliando consideravelmente o debate sobre as políticas de inclusão social para o surdo.

\section{O brincar da criança surda}

Sabe-se que $95 \%$ das crianças surdas são filhas de pais ouvintes, o que as impede de adquirir naturalmente a linguagem oral, que é utilizada pelo grupo ouvinte majoritário (Góes, 1997). Além do problema comunicativo, a maior gravidade que envolve a condição de vida do surdo refere-se ao acesso, muitas vezes tardio e limitado, à língua de sinais, configurando especificidades ao desenvolvimento lingüístico e, conseqüentemente, cognoscitivo do sujeito.

Nesses termos, parece ser relevante a indagação sobre como a experiência lingüística se articula e compóe o funcionamento imaginativo do surdo. Estudos sobre seus modos de brincar podem ampliar a compreensão sobre como a criança surda se posiciona diante do mundo que a cerca, seu modo de interpretar e se expressar sensivelmente sobre o real.

Um dos primeiros trabalhos sobre o brincar de surdos foi organizado por Góes, em 1997. A autora investigou um grupo de crianças, em fase inicial de aquisição de língua de sinais, constatando em suas observações como a peculiaridade da experiência lingüística afeta as dinâmicas interativas no jogo de faz-de-conta.

O trabalho foi desenvolvido numa brinquedoteca, o que facilitava o acesso das crianças aos brinquedos. As observações, sistematizadas por episódios de cenas lúdicas, evidenciavam a tendência da criança surda em utilizar recursos gestuais e expressão corporal na composição das cenas lúdicas e uma limitação nos usos de linguagem (sinais e fala).

Apesar dessa caracterização geral, justificada pelo pouco e ainda recente contato das crianças com a língua de sinais, a pesquisa revelou 
que não havia uma impossibilidade de construção da ação simbólica, nem mesmo uma incapacidade de abstração.

A dissertação de mestrado de Ferreira (1998) seguiu as diretrizes investigativas apontadas por Góes (1997). Aquela pesquisadora, ao estudar o brincar de crianças surdas, também em fase inicial de aquisição de sinais, verificou duas dimensōes da atividade simbólica: uma referente à flexibilização de significados na brincadeira e outra relacionada aos modos de composição de papéis sociais (personagens). No primeiro caso, observaram-se três formas significativas e diferenciadas de configuração do brincar:

1) Situações em que as crianças brincavam presas aos significados dos brinquedos, manipulando objetos e construindo ações retidas às características funcionais dos mesmos (restrita utilização de recurso lingüístico);

2) Situações em que as crianças organizavam cenas lúdicas com base no uso convencional dos brinquedos, mas inserindo contextos discursivos que estavam desprendidos do uso imediato e perceptivo dos objetos, consolidando diálogos, trazendo outros elementos imaginativos para a cena, por meio de sinais e expressão corporal;

3) Situações (mais raras) em que as crianças transgrediam as imposiçôes perceptuais dos objetos, possibilitando, por exemplo, que uma cobra de tecido se transformasse em um carro e, depois, em uma moto. Esse formato de composição do brincar evidenciava uma forte presença da língua de sinais, já que a mediação simbólica possibilitava que os significados fossem negociados e alterados entre os pares nas brincadeiras (cobra/carro/moto).

No que tange às questôes relacionadas à assunção de papéis sociais pela criança surda nos momentos de brincadeiras, Ferreira (1998) identificou dois campos de análise sobre as cenas lúdicas: 1) Momentos em que as crianças agiam solitariamente; 2) Momentos em que as crianças brincavam entre pares.

No primeiro caso, a autora revelou que as crianças compunham cenas lúdicas, mas não especificavam do que brincavam. Muitas vezes, elas exploravam características físicas dos brinquedos, mas não utilizavam sinais ou outras expressões para explicitação do papel que estava 
Surdez e Inclusão Social: o que as brincadeiras infantis têm a nos dizer...

sendo encenado. É o exemplo de uma criança que, ao se apoiar numa vassoura em miniatura, faz gestos de varrer o chão, indicando ações domésticas, mas não explicita, em nenhum momento, quem efetivamente ela está representando.

Por outro lado, as brincadeiras entre pares exigiam maior caracterização dos papéis representados e as crianças se utilizavam mais intensamente dos recursos expressivos e sinais, entre outros, para compor a cena lúdica. $\mathrm{Na}$ verdade, o par (o outro) precisava entender de algum modo o que estava acontecendo, "quem encenava o quê", garantindo a continuidade da brincadeira. Mesmo assim, observou-se, como no primeiro caso, que as crianças não nomeavam, seja para si ou para o outro, quais papéis representavam.

Tal situação curiosa despertou o interesse investigativo por ser a nomeação dos papéis, sem dúvida, um importante aspecto para o desenvolvimento das brincadeiras. As crianças freqüentemente anunciam, direta ou indiretamente, seus personagens (“- Eu sou a mãe!" ou “- Vem, filha, colocar a fralda!") e o aspecto discursivo parece ser de central relevância para a configuração dos papéis encenados.

Por isso, na base analítica do material pesquisado, a autora sugeriu que tal especificidade no modo de estruturação das brincadeiras (se comparada ao faz-de-conta de crianças ouvintes, por exemplo) pode estar relacionada à peculiaridade lingüística das crianças surdas pesquisadas, por estarem em fase inicial de aquisição dos sinais (que significa, no mundo oral, aprender a falar). Então, é compreensível que elas não saibam alguns sinais, que confundam outros, que não designem o sinal correto (para algum objeto ou intenção) e que "errem" na sua realização (da mesma forma que a criança ouvinte "erra" ao falar e trocar fonemas, no início da aquisição oral).

A autora também salientou que as crianças, além de estarem aprendendo a sua língua natural, também estão "aprendendo a brincar". Portanto, elas podem (ainda) não saber combinar sinal-gesto-manipulação de objetos para caracterização do que estão brincando e na construção de quem representam.

Góes (2005), expandindo o interesse de pesquisar as relações entre surdez, linguagem e imaginação, realizou outro estudo sobre o fazde-conta em crianças surdas. A autora buscou evidenciar os modos pe- 
los quais a linguagem participa da construção imaginária, partindo da videogravação de cenas lúdicas em uma brinquedoteca com crianças de cinco a seis anos de idade, em fase inicial de aquisição da Língua Brasileira de Sinais, no contato com surdos adultos. A análise do material foi organizada em dois temas: a) a construção de enredos e personagens e b) o modo como os enunciados se articulavam na construção desses enredos.

Em linhas gerais, pode-se concluir, entre outros, que as crianças surdas compuseram uma grande variedade de temas lúdicos; elas brincavam de casinha, motorista, supermercado, entre outros, construindo "um plano ficcional". Essa configuração múltipla de cenas lúdicas indicava, conseqüentemente, a assunção de variados personagens pelos quais a criança vivenciava "eus fictícios". A exploração sobre a posição que ocupa o outro na cultura ("imagens de outros") é considerada, pela autora, como a experiência de viver os acontecimentos da vida, apoiada nos aportes teóricos de M. Bakhtin (1992).

A discussão levantada por Góes (2005) parece ser de extrema relevância para o presente trabalho. A idéia de vinculação entre a assunção de papéis como essa exploração de "eus fictícios", como denomina a autora, é muito profícua, permitindo desdobramentos para reflexão sobre o brincar como importante esfera de investigação sobre os modos de expressão e interpretação que a criança realiza acerca da sua vivência cultural (Silva et al., 2003).

De fato, além de viver os acontecimentos da vida, ao brincar, a criança parece interpretá-los através de uma ação criadora. Ou seja, ela expressa ludicamente a forma como a cultura a afeta e a constitui, indicando a dimensão afetiva constitutiva do faz-de-conta.

$\mathrm{Na}$ medida em que a brincadeira pode ser entendida por meio de bases interpretativas e expressivas da infância, portanto embrionariamente artística (como afirma Tezza, 1996), parece ser interessante indagar como as crianças surdas se posicionam ludicamente acerca de suas experiências em uma sociedade lingüística oral que, na maioria das vezes, parece excluí-las das açôes cotidianas, das agendas culturais.

Em outros termos, como a criança surda se apropria do universo ouvinte na composição das cenas lúdicas e na utilização de brinquedos? Como se configura a formatação de personagens vinculados aos espaços de experiência com o mundo oral? 
Surdez e Inclusão Social: o que as brincadeiras infantis têm a nos dizer...

\section{O estudo de campo: características}

Pesquisas sobre o brincar apresentam como preocupação central a delimitação do local em que o material investigativo será levantado. Os eventuais espaços escolhidos pelo pesquisador devem propiciar o encontro entre crianças, obter diversidade de recursos materiais e ser respeitosos com relação ao interesse delas, de forma que possam brincar do que desejam.

Os parques, as escolas e, em especial, as brinquedotecas parecem configurar contextos favoráveis para a emergência do faz-de-conta. Partindo desse argumento e objetivando melhor entender o modo de funcionamento lúdico das crianças surdas, o Grupo de Pesquisa Pensamento e Linguagem (GPPL/UnICAMP, Campinas) sistematizou um banco de dados, em forma de videogravação, em que são focalizadas atividades lúdicas de crianças surdas, em uma brinquedoteca de Campinas.

Com base nesse material coletado e transcrito, ${ }^{6}$ o presente artigo busca discutir os modos de composição da cena lúdica e sua relação com a maneira das crianças se posicionarem diante das experiências que travam com a sociedade ouvinte. Para tanto, torna-se necessário identificar: a) o grupo de crianças investigadas e b) características do local pesquisado.

O grupo era composto por uma menina e sete meninos, entre seis e sete anos de idade, e a condição de surdez enquadrava-se entre o grau profundo e severo. Todas eram filhas de pais ouvintes, o que sugeria pouco (ou mesmo nenhum) contato com os sinais na fase inicial da infância.

Entretanto, desde o ano anterior às videogravações, as crianças estavam realizando atividades opcionais com instrutores surdos, para que pudessem aprender a Língua Brasileira de Sinais.

O grupo freqüentava quinzenalmente a brinquedoteca, em horários previamente agendados (turno da manhã, em um período de uma hora e meia). As crianças tinham toda liberdade para escolha dos brinquedos e, muitas vezes, os adultos participavam das cenas lúdicas.

A brinquedoteca, por sua vez, funcionava em uma sala de 40 metros quadrados, coberta por prateleiras fixadas nas paredes, nas quais se encontravam expostos todos os brinquedos (kits de supermercado, casinha, posto de gasolina, cozinhas etc.). Além disso, o espaço era subdividido em diferentes "cantos": 
1) Canto do Camarim - localizado em um tablado circular, que possuía um cabideiro com várias fantasias, um espelho fixado na parede, material de maquiagem, mesas e cadeiras etc.

2) Canto das Almofadas - com bichos de pelúcia e bonecas.

3) Canto da Música - composto por reproduçôes em miniatura de brinquedos, piano e variados instrumentos musicais.

A construção dos dados envolveu exame dos conjuntos de vídeos do grupo focalizado e seleção de episódios de interesse à presente discussão, explorando as questóes relacionadas à reflexão acerca do brincar de crianças surdas.

\section{Análise dos dados: episódios de faz-de-conta}

O foco da análise dos episódios sobre o brincar pretende evidenciar o modo como a criança se expressa e interpreta, por meio das cenas de faz-de-conta, o universo ouvinte que a circunda.

Num desdobramento, pretende-se articular a experiência lúdica com a discussão sobre inclusão social do surdo, repensando, por meio dos episódios, os sentimentos, as percepções da criança sobre a posição que ocupa numa sociedade oralizada. Para tanto, dois campos categoriais serão analisados:

1) Modos de configuração de objetos-pivô que evidenciam e, muitas vezes, são restritos à experiência do universo ouvinte.

2) A assunção de papéis sociais específicos à experiência com o mundo oral. ${ }^{7}$

1) Sobre a composição de cenas lúdicas instanciadas por brinquedos que fazem diretas referências à vivência ouvinte

Episódio 1: o telefone 1

O Emerson pegou um telefone e o mostra para Cláudio, apontando o instrumento para o colega (que está na sua frente). Cláudio, por sua vez, sinaliza para Emerson:

- Quer (balança cabeça afirmativamente) pegar telefone (a mão dele pega no telefone). 
Surdez e Inclusão Social: o que as brincadeiras infantis têm a nos dizer...

O Emerson, mostrando o telefone para Cláudio, aperta os botôes como se estivesse fazendo uma ligação. Então, Cláudio tenta pegar o telefone do Emerson, mas este faz-de-conta que está conversando com alguém; vira-se de costas para o colega e vocaliza alguns sons, imitando uma conversa.

Episódio 2: o telefone 2

Vinicius se dirige ao telefone, que se encontra em cima da mesa, e observa o instrumento atentamente. Ele, então, brinca com o telefone e vocaliza alguns sons. Em seguida, pára, mantendo o telefone no ouvido, como se esperasse a resposta do "outro". Torna a vocalizar, coloca o telefone no gancho e se dirige à monitora.

Embora curtos, os episódios demonstram claramente o modo como as crianças se apropriam de instrumentos que são utilizados por ouvintes. Emerson, por exemplo, brinca ao telefone, fazendo-de-conta que está apertando os números e vocaliza como se estivesse falando com alguém do outro lado da linha. Ele tenta incorporar Cláudio à sua atividade, mas ambos parecem não conseguir negociar facilmente o que vai ser desenvolvido na cena e, por isso, acabam se desencontrando. Vinicius, por sua vez, além de vocalizar, parece configurar um diálogo, ao esperar um outro responder o seu enunciado.

Certamente, Cláudio, Vinicius e Emerson conhecem esse instrumento, a partir de suas vivências sociais mais amplas e, por isso, sabem para que serve e como é utilizado. O telefone significa falar com alguém ausente fisicamente, mas seu uso não é facilmente acessível aos surdos.

Compreendendo a natureza sociogenética da brincadeira (Vigotski, 1987 e 1988), sua relação com a dimensão expressiva e interpretativa da criança sobre a sociedade mais ampla que a circunda (Góes, 2000; Silva et al., 2003), muitas consideraçôes podem ser efetuadas acerca da posição social ocupada pelo surdo em sua relação com o mundo da oralidade. Outrossim, os episódios deflagram que a motivação do brincar - ao estar, também, instanciada pela necessidade/desejo do sujeito - reflete o interesse do surdo pela experimentação de instrumentos pertencentes comumente à sociedade majoritária (o telefone, por exemplo).

Isso significa afirmar que a criatividade lúdica possibilita o deslocamento da criança surda do lugar social que concretamente ocupa, abarcando para si a experiência de ser ouvinte, exercitando e flexibilizando 
outros modos de se realizar no mundo. Ao ser "ouvinte", pela imaginação, a criança amplia, conseqüentemente, a compreensão sobre si mesma e sobre a condição da própria surdez. A brincadeira permite a apreensão mais profunda das relações e seus dramas (mãe/filha; aluna/ professora; surdo/ouvinte etc.), pois a criança age submetendo-se às regras de comportamento que, cotidianamente, não são notadas por ela. Sobre isso, Vigotski (1988, p. 108) comenta:

Na vida, a criança comporta-se sem pensar que ela é irmã de sua irmã. Entretanto, no jogo em que as irmãs brincam de 'irmãs', ambas estão preocupadas em exibir seu comportamento de irmã; o fato de as duas irmãs terem decidido brincar de irmãs induziu-se a adquirir regras de comportamento (...). Neste exemplo a ênfase está na similitude de tudo aquilo que está ligado ao conceito que a criança tem de irmã; como resultado do brincar, a criança passa a entender que as irmãs têm entre elas uma relação diferente daquela que têm com outras pessoas. O que na vida passa despercebido pela criança torna-se uma regra de comportamento no brinquedo.

$\mathrm{Na}$ medida em que a criança efetua esses deslocamentos entre sua impossibilidade concreta (não escutar) e a possibilidade imaginada (ouvir), assumindo o uso de instrumentos restritos à experiência do mundo oral, ela consolida, pelos recursos da imaginação, a experiência de trocas sociais que, na maioria das vezes, lhe é negada, ou limitada, em função das diferenças lingüísticas.

Assim, além de brincar de ser ouvinte, a criança também exercita uma forma de estar no mundo, efetuando inscrições lúdicas indicadoras de um pertencimento social embrionário. A interpretação e a construção expressiva sobre elementos da sociedade ouvinte, no faz-de-conta, parecem demonstrar o desejo e um estado de pertencimento social da criança surda.

\section{2) Sobre a assunção de papéis sociais específicos à experiência no mundo oral}

Episódio 3: o show

Lucas está em cima de um tablado, usando óculos e brincando de imitar cantor. Ele faz-de-conta que está tocando guitarra; movimenta o corpo para os 
Surdez e Inclusão Social: o que as brincadeiras infantis têm a nos dizer...

lados, balança a cabeça, ajoelha mexendo o corpo para frente e para trás, como se fosse um cantor de rock.

Vinicius, observando atentamente seu colega, aproxima-se e começa a imitá-lo.

De repente, Lucas desloca-se para uma mesa e pega óculos escuros, que estavam em cima dela. Então, troca os óculos, aproxima-se de Vinicius oferecendo o sobressalente.

Vinicius aceita a oferta do colega e ambos continuam a brincar de cantores, parecendo que estão realizando um show de rock. ${ }^{8}$

No episódio apresentado acima, Vinicius e Lucas brincam de ser cantores. Toda a estruturação da cena, o cenário (tablado) e a vestimenta (o uso de óculos) demonstram claramente que ambos fazem-de-conta que estão tocando guitarra, cantando. Os movimentos corporais, em especial os da cabeça, reforçam essa idéia geral e a sensação para quem está de fora da brincadeira é a de que eles estão apresentando um show de rock.

O campo de análise desse episódio é muito amplo e inesgotável, por isso torna-se relevante revisitá-lo freqüentemente. Numa primeira delimitação, conclui-se que as crianças assumem papéis exclusivos à experiência ouvinte.

Realmente, cantar um rock ou tocar instrumentos é uma ação muito pouco provável de ser executada por um surdo. Mas, novamente, a necessidade/desejo de compreender e se inserir na agenda cultural da sociedade lingüística majoritária são tão contundentes que as crianças inscrevem-se, pela imaginação, nesse cenário que se apresenta marcado por uma interdição, uma limitação (a surdez).

Nesses termos, a idéia geral de que a surdez causaria uma "certa apatia" ou dificuldade frente à integração social é, aqui, questionada. Os episódios demonstram, em especial o último, que a criança surda está na sociedade oral, muito antes de dominar seus registros formais de escrita ou fala.

As práticas de oralização de surdos, que sempre centralizaram esforços na aquisição da fala para efetiva inclusão social, parecem não considerar experiências anteriores que a criança surda consolida e que demonstra sua inscrição no universo oral.

$\mathrm{Na}$ verdade, as brincadeiras, entre outras atividades, deflagram que a surdez, a língua de sinais, a identidade do surdo se constituem em meio a um permanente diálogo com a sociedade ouvinte, numa dinâmica rica entre diversidades culturais e lingüísticas. 
A complexa experiência, guiada pela assunção do papel social e das regras comportamentais fixadas pelo contexto da cena averiguada acima - "ser cantor num show de rock" -, evidencia, entre outros, que a criança não está alienada do que a cerca, ela não está surda para o mundo. Brincar, ver brincando, participar da brincadeira etc. são formas (não únicas) de compreender o que as crianças sentem, pensam e produzem acerca do mundo que as rodeia.

\section{Considerações finais}

Como pode ser visto, a brincadeira é uma das atividades mais recorrentes da experiência infantil. Nas práticas cotidianas, é comum verificar crianças brincando de pique, de correr, de jogos de regras e de casinha. Cada brincadeira é vivida como um momento em si, rico pela sua multiplicidade e diversidade conceitual.

Para a corrente histórico-cultural, no faz-de-conta as crianças brincam porque necessitam e desejam compreender a sociedade adulta que as cerca, (re)contextualizando aspectos do mundo adulto, apreendendo regras de comportamento e assumindo papéis sociais específicos.

Muitos autores contemporâneos, como citado anteriormente, exploram essa esfera sociogenética do brincar e os trabalhos têm indicado os modos de composição lúdica das crianças, apontando os processos de flexibilização de significados, da libertação do campo perceptivo, da emergência de competências criativas e da expansão do funcionamento imaginativo.

Nesses termos, a brincadeira também se configura como campo rico para se observar a forma pela qual a criança pequena expressa e interpreta o mundo que a cerca, na medida em que tal atividade se configura como experiência artística embrionária, formadora do campo sensível da criança.

Partindo desses argumentos, o presente estudo pretendeu analisar o brincar de crianças surdas, buscando refletir sobre suas percepções ("leituras e escritas"), compreensões e produçōes criativas relacionadas ao universo ouvinte. Ou seja, a partir das cenas lúdicas, evidenciou-se como os sujeitos pesquisados revelam sua visão sobre a sociedade majoritária e suas dinâmicas relacionais. 
Surdez e Inclusão Social: o que as brincadeiras infantis têm a nos dizer...

Para tanto, dois campos categoriais foram explorados: 1) composição de cenas lúdicas instanciadas por brinquedos que fazem diretas e/ou exclusivas referências à vivência ouvinte (como no uso do telefone - episódios 1 e 2);2) assunção de papéis sociais específicos à experiência no mundo oral (episódio 3).

No campo de análise do material videogravado, as esferas do desejo e da necessidade foram apontadas como motivadoras da consolidação de cenas lúdicas que se apóiam no uso de instrumento e de assunção de papéis exclusivos à experiência do mundo oral. Além disso, algumas análises foram feitas sobre a posição do surdo diante da sociedade ouvinte, tanto do ponto de vista da implicação dessa vivência para o alargamento da experiência subjetiva, como na identificação da esfera de inserção social (ser e estar no mundo), ou melhor, da inscrição do sujeito na cultura, por meio das brincadeiras.

Todas essas reflexões orientam-se para a análise sobre a posição participativa do surdo, contrariando a idéia de que a surdez provoca uma "apatia social”. Os dados exploram a relação da composição de cenas lúdicas como implicadas a um conceito mais amplo de inclusão social, evidenciando que a criança surda já dialoga com a sociedade majoritária.

A concepção de que o surdo (por não falar e ouvir) não tem como, efetivamente, participar da sociedade e está, portanto, alheio a ela (fora), bem como a noção de que para estar incluído (dentro) tem-se que, necessariamente, agir como ouvinte (como sugere parte considerável das propostas de caráter integrador - ver Sassaki, 1997), está, aqui, criticamente contestada.

De fato, o debate da inclusão do surdo não pode estar balizado por uma linha foraldentro do pertencimento social. Os homens são sujeitos sociais e, de alguma forma, socialmente, estão incluídos.

O debate da inclusão social parece se direcionar para um outro vetor, mais especificamente as práticas de participação social e exercício de cidadania, efetivado por cada membro da sociedade, nesse caso, os surdos. Tal princípio revela a urgência de ampliação de pesquisas sobre como o próprio sujeito entende e vê a sociedade e suas dinâmicas relacionais. O brincar é uma das esferas ricas para análise dessa questão.

Por isso, é de grande relevância a conscientização de que toda a sociedade e suas instâncias institucionais (em particular, a escola) e participativas (os movimentos sociais) precisam atentar-se especificamen- 
te para uma escuta sobre o que o surdo tem a dizer em relação a sua posição de pertencimento social, respeitando a sua forma de (se) dizer aspecto lingüístico: o uso de sinais - e considerando os processos afetivos que estão implicados e são constitutivos/característicos da experiência de grupos sociais minoritários.

$\mathrm{Na}$ verdade, as cenas lúdicas são indicadoras de questôes mais amplas e profundas relacionadas às tensões surdo/ouvinte. Múltiplos aspectos precisam ser aprofundados e o debate sobre as políticas de inclusão social precisa considerar prioritariamente os surdos, suas narrativas, desejos e necessidades.

Recebido em outubro de 2005 e aprovado em fevereiro de 2006.

\section{Notas}

1. $\mathrm{O}$ autor tece argumentos sobre a imaginação na $5^{\mathrm{a}}$ Conferência do livro $O$ desenvolvimento psicológico na infância (2000) e nas discussōes iniciais do texto "Imaginacíon y el arte en la infancia" (1987).

2. Góes (2000) demonstra que a criança cria seqüências lúdicas desdobradas em dois tipos de cenários: a) cenário representado, em que se apóia no uso de objetos disponíveis e nas relaçōes com parceiros presentes; b) cenário conjetural, estruturado a partir de situaçôes e personagens não encarnados, que se tornam presentes pelos enunciados produzidos no desenrolar da atividade.

3. A "vivência performática" da criança pequena, nos momentos lúdicos, não se orienta intencionalmente para uma platéia. Na maioria das vezes, os pequenos brincam para si mesmos (ou para/com o seu grupo) sem lhes preocupar quem está vendo, filmando ou assistindo o faz-de-conta. Contudo, ressalta-se, aqui, a possibilidade de contemplação do espectador (daquele que está fora da cena), que confere acabamento estético à atividade (Tezza, 1996).

4. As relaçôes entre o brincar e a arte são pouco discutidas nos trabalhos em Psicologia. Entretanto, torna-se curioso ressaltar que parte considerável das discussões conceituais sobre a brincadeira infantil e, principalmente, suas denominaçóes aporta-se na nomenclatura teatral Os termos personagem, jogo de papel, cenários lúdicos, entre outros, são empréstimos do teatro, indicando uma relação interessante entre o brincar e essa esfera de atuação artística.

5. Ver De Carlo (1997) e Padilha (2000), entre outros.

6. A transcrição dos episódios de brincar baseou-se em seis horas de fitas videogravadas (banco de dados GPPL). A transcrição dos vídeos para o presente artigo foi efetuada com a colaboração de uma auxiliar de pesquisa, que era uma pessoa surda usuária da Língua Brasileira de Sinais.

7. Os nomes das crianças apresentados nos episódios de pesquisa são fictícios.

8. Os episódios 2 e 3 já foram publicados no livro de Silva (2002). Entretanto, para esse artigo, a análise do material videogravado seguiu outras discussões. 
Surdez e Inclusão Social: o que as brincadeiras infantis têm a nos dizer...

Referências bibliográficas

BAKHTIN, M. Estética da criação verbal. São Paulo: Martins Fontes, 1992.

DE CARLO, M.M.R.P. Por detrás dos muros de uma instituição asilar: um estudo sobre o desenvolvimento humano comprometido pela deficiência. 1997. Tese (Doutorado) - Faculdade de Educação, Universidade Estadual de Campinas, Campinas.

FERREIRA, D.N.S. O brincar e a linguagem: um estudo do jogo de faz-de-conta em crianças surdas. 1998. Dissertação (Mestrado) - Faculdade de Educação, Universidade Estadual de Campinas, Campinas.

GÓES, M.C.R. A formação do indivíduo nas relações sociais: contribuições teóricas de Lev S. Vigotski e Pierre Janet. Educação \& Sociedade, Campinas, v. 21, n. 71, p. 116-131, 2000.

GÓES, M.C.R. O brincar de crianças surdas: examinando a linguagem no jogo imaginário. Disponível em: <http://www.educacaoonline.pro.br/ o_brincar_de_criancas_surdas.asp> Acesso em: 23 jun. 2005.

GÓES, M.C.R. A linguagem e o funcionamento imaginário no brincar da criança surda. Relatório CNPq, 1997.

MARX, K. Antologia filosófica. Rio de Janeiro: Petrópolis, 1971.

MARX, K. Ideologia alemã (Feuerbach). 11. ed. São Paulo: HUCiTec, 1999.

OLIVEIRA, Z.R. Jogo de papéis: uma perspectiva para análise do desenvolvimento humano. 1988. Tese (Doutorado) - Instituto de Psicologia, Universidade de São Paulo, São Paulo.

OLIVEIRA, Z.R. Interações infantis em creche e a construção de representações sociais de gênero. Caderno ANPEPP, Recife, v. 1, n. 4, set. 1996.

PADILHA, A.M.L. Perspectivas que se abrem para a educação especial. Educação \& Sociedade, Campinas, v. 21, n. 71, p. 197-220, 2000.

PIAGET, J. A formação do símbolo na criança: imitação, jogo e som, imagem e representação. Rio de Janeiro: Zahar, 1975.

PINO, A. A constituição e os modos de significação do sujeito no contexto da pré-escola. Caderno ANPEPP, Recife, v. 1, n. 4, set. 1996. 
ROCHA, M.S.P.M.L. Não brinco mais: a (des)construção do brincar no cotidiano educacional. Ijuí: Unijuí, 2000.

ROCHA, M.S.P.M.L.; GÓES, M.C.R. Exploraçôes sobre o desenvolvimento da operação com signos na atividade lúdica: relações entre o imaginário e o real. Trabalho apresentado na $23^{\text {a }}$ Reunião Anual de Psicologia, Ribeirão Preto, 1993.

SASSAKI, R.K. Inclusão: construindo uma sociedade para todos. Rio de Janeiro: WVA, 1997.

SILVA, D.N.H. Como brincam as crianças surdas. São Paulo: Plexus, 2002.

SILVA, D.N.H.; DIAS, M.; ABREU, R. Brincadeira, linguagem e imaginação: modos da criança pequena "ler" e "escrever" sobre o mundo da cultura. In: ENCONTRO INTERNACIONAL LINGUAGEM, CUlTURA E COGNIÇÃO, 2., 2003, Belo Horizonte. Anais... Campinas: Graf. FE, 2003.

TEZZA, C. Sobre o autor e o herói: um roteiro de leitura. In: FARACO, C.A. et al. Diálogos com Bakhtin. Curitiba: UfPR, 1996.

VIGOTSKI, L.S. Imaginación y el arte e infancia. México: Hispanicas, 1987.

VIGOTSKI, L.S. A formação social da mente. São Paulo: Martins Fontes, 1988.

VIGOTSKI, L.S. Teoria e método em psicologia. São Paulo: Martins Fontes, 1999.

VIGOTSKI, L.S. O desenvolvimento psicológico na infância. São Paulo: Martins Fontes, 2000. 